\title{
Forming an X-ray Analysis Society
}

In 1991, discussions were initiated at the Pacific International Conference on X-ray Analysis of Materials, PICXAM-I, concerning the formation of a society devoted to the topic of X-ray analysis including diffraction, fluorescence, and related fields. At that time the concern was the extremely minor role afforded powder diffraction in the American Crystallographic Association and the lack of a true societal home for the XRF attendees at the Denver X-ray Conference, DXC. Although the discussions were well attended by the conferees and were lively, the ultimate decision was that the formation of a society was premature at that time.

Now, there is need to resume these discussions. There is still a lack of recognition for the analytical aspects of the field both nationally and internationally. Another reason is the future of the DXC and other similar conferences throughout the world. The primary organization responsible for the DXC has been the University of Denver, and the DXC has served the function of the principal meeting in North America on X-ray analytical applications. The Australian X-ray Analytical Association, AXAA, sponsors meetings within Australia in alternate years, but the organization of these meetings is primarily in the hands of local committees. The conditions are similar for the European Powder Diffraction International Conference, EPDIC and for the European EDXRF Conference. There is.no central organization responsible for the continuity of the alternate year meetings. Once the site for the next meeting has been decided, local committees are responsible for individual meetings, and much of the experience and continuity from past meetings is lost. In addition, the Japanese Commission on Powder Diffraction Data, JCPDD, in cooperation with the Japanese Society for X-ray and Spectrochemical analysis, organizes meetings in Japan and is currently planning PICXAM-III. PICXAM is envisioned to be an international meeting bringing together all the individual geographic components of $\mathrm{X}$-ray analysis. With this proliferation of activity in different parts of the world, an international X-ray Analysis Society with geographic branches may now be appropriate.

The need for immediate discussions on such a society are enhanced by the need for some group to assume the responsibilities of the DXC. At the end of the 1997 DXC, Paul Predecki will retire as active chairman of the DXC Organizing Committee. There is no individual in the Denver area who is available to continue in this capacity. Also the University of Denver will no longer be a sponsoring organization. The International Centre for Diffraction Data, ICDD, is considering what role it may play in the future of this meeting, but it is not the right organization to play the role of a society. The DXC Organizing Committee will still exist, but it really needs the support of a society to continue the high quality of the DXC.

The primary function of the ICDD is to maintain and produce the Powder Diffraction File and related products and to sponsor projects and meetings on powder diffraction. The membership in ICDD is a working group of dedicated individuals responsible for overseeing the development of products and procedures for improv- ing the utility and accuracy of powder diffraction. The ICDD does have a strong interest in the fluorescence field, but it is small compared to its powder diffraction activities. The ICDD has been a sponsor of the DXC, EPDIC, and AXAA meetings, but its membership structure is quite different from the society needed to ensure the future of the exchange of information at meetings and through publications.

It is important to realize that there is no national or international forum for the XRF community outside of the DXC. We must emphasize that the ICDD is completely dedicated to maintaining the DXC in its present (and historical) form, mainly giving equal importance to XRD, XRF and related topics, applications and theoretical interests. ICDD will also assure that the DXC Organizing Committee will retain its autonomy. In order to continue the present method of operation, it has been proposed that the ICDD establish a Subcommittee on X-ray Fluorescence.

The existence, role, and future of Powder Diffraction and the Journal of X-ray Spectrometry are other considerations for a society. Although these publications are doing well, both would benefit from formal association with a single organization of large membership representing the full field of X-ray analysis.

One question to consider is the coverage of such a society. The discussions to date have primarily been centered on X-rays as the tool for analysis, but neutrons are becoming more important as an analytical tool also. There are also many industries using national synchrotron facilities for analytical applications. Any discussion of the formation of a society needs to cover all the possibilities.

The term "analytical" perhaps needs some clarification in the context of such a society. Analytical now goes far beyond qualitative or quantitative determination of phases or elements present in a material. Any measurement of properties by diffraction, fluorescence, reflectometry, or related technique, including the determination of crystal and surface structures, strain measurement, lattice parameters, texture, crystallite size, and radial distribution analysis, can be considered an analytical application if $\mathrm{X}$-rays or neutrons are employed. Electrons are not considered here only because there is already the Electron Microscope Society.

New discussions on the formation of an X-ray Analytical Society were held at the 1996 DXC/CPD (IUCr, Commission on Powder Diffraction) meeting. Further input is needed from those who could not attend any of the discussions or individuals with additional input. This editorial is an appeal for interested persons to let their views be known. At present, the DXC Organizing Committee is acting as the collecting point for ideas. Anyone wishing to provide input on the pros and cons for forming a society may send comments to any member of the DXC Committee. E-mail is certainly the most convenient mode. My snail mail address and FAX number are on the title page of this issue.

\section{Committee}

Paul Predecki Robert L. Snyder Randall Barton ppredeck@odin.cair.du.edu snyder@kcgl1.eng.ohio-state.edu bartonr@csoc.dnet.dupont.com

Ron Jenkins
Mary Ann Zaitz
Victor Buhrke
jenkins@icdd.com
mzaitz@vnet.ibm.com
vbuhrke@aol.com
Ting C. Huang

Deane K. Smith

DXC Secretary
Deane K. Smith

Editor-in-Chief 